José Luis Piñar Mañas

Catedrático de Derecho Administrativo. Universidad San Pablo-CEU de Madrid.

\title{
Presentación: El modelo de función pública como sistema complejo y abierto
}

El Derecho Administrativo no «es». El Derecho Administrativo "está siendo». Está formándose trabajosamente como sistema complejo, abierto, nunca cerrado. Sistema complejo que en la medida en que se abra conseguirá su clausura. Lo cual, seguramente, significa cuestionar la permanencia de los dogmas (o de algunos de ellos). Lo mismo cabe decir del modelo de empleo con las Administraciones Públicas: está constantemente haciéndose, sin que sea conveniente intentar cerrar las puertas a planteamientos nuevos. Este modelo también es complejo y abierto.

Cuando hablo de sistema abierto no me refiero a la idea que sobre tal concepto se tiene usualmente al hablar del empleo público (sistema abierto-sistema laboralizado). Me refiero al concepto que de él ha dado el filósofo francés Edgar Morin (París, 1921): frente a los planteamientos cartesianos, que han controlado la «aventura del pensamiento occidental desde el siglo XVII [y] han permitido, sin duda, los enormes progresos del conocimiento científico" ${ }^{1}$, MorIN, aun admitiendo que es, desde luego, necesario poner orden en el conocimiento, propone un cambio

\footnotetext{
1 Introduccion al Pensamiento complejo, Gedisa, Barcelona, 1994, págs. 29-30.
} 
radical: él llama la atención acerca de la complejidad del pensamiento. Todo conocimiento, señala Morin, uopera mediante la selección de datos significativos y rechazo de datos no significativos: separa (distingue o desarticula) y une (asocia, identifica); jerarquiza (lo principal, lo secundario) y centraliza (en función de un núcleo de nociones maestras). Estas operaciones, que utilizan la lógica, son de hecho comandadas por principios «supralógicos» de organización del pensamiento o paradigmas, principios ocultos que gobiernan nuestra visión de las cosas y del mundo sin que tengamos conciencia de ello" ${ }^{2}$. Pues bien, los paradigmas prevalentes en el conocimiento (orden, ideas claras) deben considerarse, estima Morin, superados. Propone una «epistemología de la complejidad» ${ }^{3}$ y reivindica la noción de sistema abierto: «el sistema no puede ser comprendido más que incluyendo en sí al ambiente, que es a la vez íntimo y extraño y es parte de sí mismo siendo, al mismo tiempo, exterion ${ }^{4}$.

El Derecho Administrativo es un sistema complejo y abierto que ha vivido y vive de paradigmas. Muchos de los cuales resurgen últimamente con especial vigor al objeto de ser o bien reafirmados o bien denostados.

Y el modelo de empleo con las Administraciones Públicas es también un sistema complejo (complejo como pocos) y abierto. $\mathrm{El}$ "ambiente» en el que se desarrolla ese sistema es trascendental para su propia configuración. Ese ambiente le es externo pero al mismo tiempo interno: la realidad externa del empleo público le condiciona de tal manera que termina por hacerse elemento sustancial interiorizado. Pues el empleo público está ante todo condicionado por una función: la del cumplimiento de los fines de la Administración Pública. No es posible un análisis del empleo público «en sì si no se tiene en cuenta que el régimen de tal empleo está condicionado por un factor externo: ese cumplimiento de fines; y por constantes reconsideraciones sobre su naturaleza formuladas al hilo de realidades externas (déficit público, reivindicaciones sindicales, organizaciones y reorganizaciones administrativas, etc.) que pese a ser, como digo, externas, son al mismo profundamente internas al modelo.

Por eso un número dedicado a la laboralización de la función pública, monográfico en el tema pero plural en los planteamientos, parecía de todo punto aconsejable. No porque coincida con un momento en que, una vez más, parece que se quiere aprobar

\footnotetext{
2 Op. cit., päg. 28.

3 Pág. 39.

4 Op. cit., pág. 45.
} 
una nueva regulación sobre el Estatuto básico de la función pública (si es que ese Estatuto es posible para todo el personal al servicio de las Administraciones públicas), sino porque, al margen de esa situación temporal concreta, una reflexión sobre tal argumento es siempre necesaria.

Hemos de partir, desde luego, del carácter complejo (complejidad de sustancia) del sistema de empleo público. Quiero decir que no es posible ni siquiera intentar una aproximación cartesiana -en el sentido de no dar ni un paso en el razonamiento mientras que el anterior no se considere cierto-, a la materia empleo público. En la función pública lo único cierto es que no hay un único sistema, aunque la Ley quiera tozudamente demostrar lo contrario (regulando un modelo pretendidamente general que sólo es aplicable a un porcentaje no mayoritario de empleados públicos). Y que cuando aparentemente lo hay, cede de inmediato a la realidad de las cosas. En un reciente libro preparado y presentado por SOSA WAGNER sobre parte de la obra de POSADA HERRERA ${ }^{5}$ es posible leer las siguientes reflexiones de éste con ocasión de la presentación de una proposición de Ley sobre empleados públicos que pretendía solucionar el problema de las cesantías: "Yo no creo - decía POSADA en una Sesión Parlamentaria el 6 de diciembre de 1860 - que un mal [el del nombramiento y separación de empleados públicos] que no es de ayer, es de hace tres siglos... se pueda curar con una Ley o con un reglamento; males de esta clase... no se curan sino con las costumbres; males que llevan siglos de existencia, necesitan muchos años para poderse destruir... ¿Qué sucedería, Sres. Diputados, si el Senado y el Congreso aprobasen y la Corona sancionase una Ley, en la cual fuesen declarados inamovibles... todos los empleados cuyo nombramiento he tenido el honor de proponer a S.M. desde que soy Ministro? Que nadie podría gobernar más que el actual Ministro de la Gobernación, sin que hubiera fuerza suficiente en ninguno que carezca de facultad para separar a aquellos empleados cuya lealtad o cooperación sean tibias o dudosas. Yo no quiero poner a los que me sucedan en un conflicto imposible de resolver: no quiero imposibilitar al Gobierno que nos suceda: quiero que tenga para gobernar la misma libertad que he tenido yo. Asi pues, reconociendo el mal...; reconociendo el espiritu y la verdad de algunas de las apreciaciones [de quien presentó la proposición], no estoy conforme con el remedio, ni podré aceptar una de las bases de este proyecto

5 Veinticinco Discursos y un Prólogo, Clásicos Asturianos del Pensamiento Politico, Junta General del Principado de Asturias, Oviedo, 1997. Con Estudio Preliminar de Francisco SosA. 
de ley, en la cual se consigna la casi inamovilidad de los empleados ${ }^{6}$.

¿No se basan esas palabras en un dogma hoy no sólo aparcado sino considerado contrario a la esencia misma de la actual Administración y su personal -basada en los principios de objetividad, mérito y capacidad? - ¿No se buscan hoy nuevos dogmas para justificar teóricamente un modelo de empleo público?

Pues bien, es evidente que en relación con lo sostenido hace apenas unos años (me refiero no a la época de POSADA, evidentemente, sino a los años sesenta, primero, y ochenta, después) la situación ha cambiado para quienes abogaban por una laboralización de la función pública: las ventajas que la relación laboral ofrecia respecto a la estatutaria, o han desaparecido o se han desvanecido hasta hacerlas dificilmente identificables. Así, la negociación colectiva, otrora exclusiva de los trabajadores, se ha extendido a la función pública; la defensa sindical que en algún momento se ha llevado a cabo de la laboralización hoy es dificilmente mantenible dada la política conducente a un mercado laboral cada vez más flexible. Por el contrario, son precisamente ahora las Administraciones Públicas las que coquetean con la laboralización, pues puede ofrecer mayores ventajas de eficacia, que las acredite ante los ciudadanos.

Como en Italia (véase el trabajo de CoRPACI en esta Revista), en la laboralización de la función pública en España mucho ha tenido que ver el movimiento sindical. Lo que ocurre es que algunos de los más importantes logros de las fuerzas sindicales (entre otros la rigidez del mercado laboral) hoy están desvaneciéndose como consecuencia de la nueva situación económica y de la precarización del empleo. Dicho en otras palabras: cuando parecía haberse conseguido la meta del trabajo indefinido como innegociable podía perfectamente plantearse la laboralización de la función pública (incluso como dogma), ganando así en lo que a negociación colectiva se refiere (por ejemplo). Pero cuando la negociación colectiva choca con las exigencias de contención del déficit público y cuando las fuerzas sindicales admiten la flexibilización del mercado de trabajo para conseguir más empleo, resurge una vez más con fuerza inusitada el valor de la estabilidad en el empleo que implica el régimen estatutario, y pierde fuerza la reivindicación laboralizadora.

Lo anterior no es más que una muestra de cómo el «ambiente» externo puede influir en la conceptualización del empleo con las

${ }^{6}$ Op. ult. cit., págs. 468-469. 
Administraciones Públicas. Pero lo cierto es que el jurista, pese a todo, debe intentar buscar una explicación convincente para propugnar, desde la objetividad de las normas, un sistema u otro. Aun admitiendo la complejidad (complejidad ontológica, no coyuntural) de la cuestión y su definición como sistema abierto, quizá debamos aventurar una posible explicación al porqué de la aplicación del Derecho público o del Derecho privado en la relación de empleo con las Administraciones Públicas.

En este sentido, afirmar que la Administración es una persona jurídica sigue siendo un dato esencial a la hora de definir el Derecho Administrativo y, en consecuencia, a la hora de conceptualizar la Administración Pública. No obstante, con ser trascendental, ese dato no es suficiente. Junto a ese elemento subjetivo ha de situarse un elemento objetivo; un elemento que defina claramente no sólo la vertiente estática-subjetiva de la Administración Pública sino igualmente la dinámica-objetiva, de modo que a través y en función de dicha actividad también sea posible definir el Derecho Administrativo y la Administración Pública.

En tal sentido, hemos de ser conscientes $-y$ consecuentes con ello- de que las premisas a partir de las cuales se elaboran las grandes y clásicas construcciones sobre el concepto de Derecho Administrativo no son las mismas que las que hoy han de ser tomadas en consideración. La realidad política, social y económica de hoy no es en absoluto la que dio origen a las diversas teorías que se han mantenido sobre el concepto de Derecho Administrativo (sistema abierto). Toda concepción de una rama del ordenamiento es necesariamente tributaria de una serie de factores ajenos que confluyen a configurarla. $Y$ en este sentido, los factores que en nuestros días configuran el Derecho Administrativo son los que definen e identifican la actual realidad política, social y, principalmente, económica.

En cualquier caso, sin embargo, pese a aquella indudable modificación de las premisas a partir de las cuales ha de construirse el Derecho Administrativo, es evidente que no pocas de las conclusiones a las que han llegado algunas de las concepciones clásicas son, en mi opinión, perfectamente trasladables y utilizables en nuestros días. ¿Mirar de nuevo a los clásicos cuando hemos dicho que el Derecho Administrativo - y con él el de la función pública- está en proceso de configuración constante? ¿Es acaso un contrasentido? En absoluto. Después de todo, como se ha dicho en alguna ocasión, los clásicos nunca terminan de decir lo que han de decir. Por eso conceptos como el de servicio público, potestad o prerrogativa y prestación siguen 
siendo clásicos y al tiempo novedosos. Novedosos en la medida en que, con el sentido que más atrás apuntaba, se consideren conceptos abiertos.

De modo que hemos de seguir afirmando que el servicio público es un elemento capital en la configuración de la Administración Pública. No es, por supuesto, el dato identificador definitivo, ni es posible afirmar que la ecuación servicio público-Administración Pública sea correcta sin más. Pero aquella idea de Administración servicial está o debe estar hoy plenamente en vigor.

Del mismo modo, el elemento social ha de ser hoy necesariamente tomado, de nuevo, en consideración. La definición constitucional de Estado social que contiene nuestra Constitución lo impone. La defensa de los intereses colectivos, la preocupación no meramente testimonial por los sectores sociales más desprotegidos y asimismo por la parte más desprotegida de los intereses que todos tenemos exige recuperar no pocos de los postulados que aquél formuló.

Por eso cualquier intento de conceptualizar la Administración Pública hoy debe hacerse desde la revitalización del servicio público y el mantenimiento del Estado social, que por estar en crisis no puede ser considerado modelo obsoleto. El fanático resurgir de concepciones neoliberales nos debe forzar a los iuspublicistas a reiterar los valores colectivos, so pena de que la balanza quede excesivamente inclinada hacia intereses meramente particulares. Alejandro NiETo hace años, antes de ser aprobada la Constitución, llamaba duramente la atención sobre ello, en palabras que siempre es conveniente recordar ${ }^{7}$.

7 «Hoy - señala NIETO- es fácil acusar a Duguit y Forsthoff de un fascismo larvado, puesto que, efectivamente, el fascismo comparte con ellos su repudio del orden liberal. Pero los enemigos comunes no engendran necesariamente amistad. La linea de DuGUIr y de FORSTHOFF era la correcta, como están demostrando ahora sus redescubridores. Lo que sucede es que los juristas, escarmentados - y con razón- de los excesos fascistas, han repudiado indiscriminadamente lo bueno y lo malo de las tendencias antiliberales. La ideologia liberal siempre ha atraido a los juristas por ser noble y honesta y por defender a los individuos, que es uno de los objetivos eternos del Derecho. Pero tampoco hay que olvidar los derechos de los individuos que no tienen acceso a los despachos de los abogados (¿o es que la Administración sólo tiene que ver con propietarios?) ni, mucho menos, los intereses de la colectividad. Aqui empieza la miseria del liberalismo y la necesidad de su superación. Superación que puede encarnar en el fascismo y en el socialismo, pero también en el llamado Estado social de Derecho.

Buena parte de los países occidentales han escogido, con mayor o menor sinceridad, la via del Estado social de Derecho; pero tal no es el caso de España ni, desde luego, el de sus juristas (Recuerdo que las palabras de NiETo son anteriores a la aprobación de la Constitución. Son de 1975). Entre nosotros, sigue NiETo, los administrativistas suelen bordear el Estado social de Derecho, adoptando alguna de las siguientes actitudes.

Por un lado están quienes, convencidos de la insuficiencia de los planteamientos liberales, han puesto su énfasis en la eficacia de la Administración, o sea en la necesidad de una prestación 
NIETO nos situaba, en mi opinión, en la verdadera encrucijada, de entonces y de ahora, del Derecho Administrativo. Éste, en efecto, ha de servir como medio eficaz para atender los distintos y a veces enfrentados intereses que en toda sociedad conviven, pero desde la perspectiva de lo social. Repito que no otra puede ser la concepción de la Administración Pública si atendemos a lo que nuestra Constitución dispone y configura: la Administración sirve con objetividad los intereses generales.

El Derecho Administrativo, Derecho público por excelencia, ha de atender a los intereses generales. El Derecho Administrativo ha de ser, ante todo, un Derecho social. Pero Derecho social justificado por la eficacia en la prestación objetiva del servicio público.

SORACE ha señalado que «las normas de Derecho privado son a menudo la expresión jurídica de las reglas económicas del mercado» ${ }^{8}$. Por ello, añadimos ahora, el Derecho Público, y en particular el Administrativo, debe velar por el respeto de los valores sociales que trascienden a cualquier poder público o

real de servicios públicos, al margen de los derechos individuales. Para ellos la vertiente garantizadora del Derecho Administrativo es una antigualla inoperante, y la democracia una fachada. El centro de gravedad está en el interés público, interpretado exclusivamente por el grupo de expertos que maneja el Poder, dando la menor intervención posible a los ciudadanos. Los individuos son mero objeto de la benéfica acción administrativa: no son ciudadanos, sino administrados, y si no se les niega formalmente la protección jurisdiccional, se manipula el poder de una manera tal, que su defensa queda reducida a parcelas muy estrechas, que no entorpezcan la estrategia del capitalismo monopolista, cuyos intereses representan. En su peculiar concepción del Derecho, tienden a prescindir de las formas y conciben al individuo como un límite y un estorbo para la acción administrtativa. Su base técnica es la conformación social como grado más intenso de la intervención. El sacerdote de la nueva religión es el tecnócrata; su idolo, la planificación; sus oficios rituales, la productividad y la rentabilidad, y su conjuro, la eficacia.

En el extremo opuesto están quienes se aferran a la tradición liberal, escarmentados tanto de las dictaduras políticas como de las tecnocráticas, contra las que combaten con energia admirable. Para ellos la Administración es un animal peligroso, que sólo los jueces y los abogados pueden mantener a raya, y la eficacia es un verbalismo que encubre la corrupción. Carecen de sensibilidad ante buena parte de los temas de contenido económico, tanto por su radical individualismo juridico como por concebir el Derecho como una forma. Para ellos la Administración es un límite y un estorbo a las àctividades de los particulares, y su base técrica es la defensa del individuo. Los oficiantes de esta religión siguen siendo los jueces y abogados; su ídolo, la sentencia; sus ritos, los del Derecho Procesal, y su conjuro, la legalidad.

$\mathrm{Ni}$ que decir tiene, sin embargo, que tal planteamiento es falso, puesto que ambas partes se basan en una falacia. Los tecnócratas en la falacia de que representan el interés público, cuando lo cierto es que sólo representan lo que ellos califican de interés público, entendido además como algo distinto del interés de los ciudadanos y de las comunidades. Los abogados, en la falacia de que representan el interés individual de todos los ciudadanos, cuando sólo se trata del interés de sus clientes o, en el mejor de los casos, se creen que el interés público es la suma de todos los intereses individuales): (La vocación del Derecho Administrarivo de nuestro tiempon, $R A P$, núm. 76 (enero, 1975), págs. 894-896.

8 «Tendenze innovative nell'Amministrazione Pubblica e nel Diritto Amministrativo italiani), texto mecanografiado, amablemente facilitado por el autor, pág. 8. 
privado. SUNSTEIN se ha referido a la social regulation como fundamento de la administrative substance, es decir, como elemento esencial del Derecho Administrativo contemporáneo. Regulación social que ha de ser especialmente intensa (an aggresive regulatory state) en los campos de la sanidad, seguridad, derechos civiles, y protección del medio ambiente?.

Por ahora, pues, podemos afirmar que el concepto de Administración Pública debe ser sustentado en la idea de personalidad jurídica y en la de servicio objetivo de los intereses generales. Esta prestación es precisamente el giro o tráfico administrativo en virtud de la cual aquélla adquiere todo su significado.

Ahora bien, para llevar a cabo tal servicio objetivo, la Administración puede necesitar de potestades específicas. En el ejercicio de sus funciones, en el desarrollo de su actividad, y precisamente para garantizar un mejor y más objetivo servicio de aquellos intereses, puede hacer uso de potestades que sitúan a la Administración en una especial situación de imposición frente a los particulares. Imposición, por supuesto, controlada y sometida a límites. Por ello, la idea de prerrogativa, también ésta, y por tanto también HAURIOU, sigue siendo hoy plenamente actual. Idea que dirige nuestra atención no ya hacia el sujeto (Administración) y su actividad (servicio) sino hacia el régimen jurídico en virtud del cual se rige: el Derecho Administrativo. El Derecho Administrativo es así el Derecho que garantiza el servicio objetivo de los intereses generales por encima de cualquier interés extraño, tanto privado, como - y esto es esencial - de la propia Administración. El Derecho Administrativo no es el Derecho que sirve a los intereses de la Administración, sino a los intereses generales. Es así garantizador de los derechos y del interés general. No hay mayor error entre la dogmática del Derecho Administrativo que seguir utilizando la idea de «autotutela», pues con las prerrogativas que ésta comporta no se protegen en absoluto los intereses propios de la Administración. Ésta no se tutela a sí misma (que es lo que expresa la idea de autotutela), sino que ha de servir los intereses generales. Sólo en función de este objetivo adquiere pleno sentido la llamada «autotutela».

La que aquí mantengo es, en definitiva, una concepción integradora de las grandes construcciones conceptuales del Derecho Administrativo y de la Administración Pública. Ésta queda definida por las ideas de personalidad, servicio objetivo e intereses generales. Aquél por la de prerrogativa aplicada a esa actividad servicial. Por ello cabe decir que hoy por hoy la Administración

9 «Administrative Substance», en Duke Law Joumal, Volume 1991, junio, núm. 3, pág. 610. 
Pública se configura como persona jurídica objetivamente servicial de los intereses generales que en el ejercicio de las potestades que el ordenamiento le otorga para el desempeño de sus funciones actúa sometida al Derecho Administrativo, que es su Derecho propio y específico.

Esto significa que cuando la Administración ejerce tales potestades debe aplicar necesariamente el Derecho Administrativo en todo su detalle. No hay lugar para otras ramas del ordenamiento, salvo cuando sea necesario aplicarlas con carácter meramente supletorio (lo cual exige que no haya norma aplicable en el ámbito del Derecho Administrativo). Pero, dado que la idea de prestación servicial objetiva es omnipresente en toda actividad (sea cual fuere) de la Administración Pública es por tanto necesario que la Administración Pública atienda en todo momento a los principios que el Derecho Administrativo contiene como ordenamiento específico del servicio de los intereses generales, principios que se encuentran recogidos en la Constitución: objetividad, imparcialidad, eficacia.

Lo cual nos permite llegar a la siguiente conclusión: toda la actividad de la Administración Pública, sea ésta fruto del ejercicio de una potestad o sea manifestación de mera gestión o prestación, está vinculada y por tanto sometida a los principios constitucionales que condicionan el servicio obietivo de los intereses generales, lo cual exige actuar de acuerdo a las premisas de objetividad, imparcialidad y eficacia. La actividad que suponga el ejercicio de potestades está sometida sin embargo y necesariamente al entero Derecho Administrativo en todo su detalle, sin que sea posible abstraerse de la aplicación de norma alguna del mismo.

Lo cual se traduce en que el Derecho Administrativo está siendo en todo caso -aqui y ahora- el Derecho propio y específico de la Administración Pública y habrá de ser siempre aplicado por ésta, en todo su detalle (ejercicio de potestades) o respetando cuando menos (en otro caso) los principios esenciales que lo informan.

De esta forma, incluso la actividad de Derecho privado de la Administración Pública ha de respetar tales principios, sin que en ningún caso sea admisible su inobservancia. Lo cual es algo que, por lo demás, no es en absoluto nuevo en nuestro Derecho, sino algo perfectamente conocido en los ámbitos en los que más fuertes son, por cierto, las presiones del Derecho privado: la contratación y el régimen de personal.

Lo anterior condiciona cualquier intento de liberalización plena de la función pública. Pero también cuestiona cualquier 
pretensión de sometimiento exclusivo al Derecho Administrativo de todo el personal al servicio de las Administraciones públicas ${ }^{10}$.

En definitiva, pese a la complejidad y apertura del sistema bien podría afirmarse que donde encontremos ejercicio de potestades públicas el Derecho aplicable debe ser el Derecho Administrativo. Lo cual no significa que éste no pueda o deba acoger, sin preocupación alguna, elementos (los necesarios y posibles) del Derecho privado que de alguna manera se «administrativizany al adaptarlos al empleo público.

En cualquier caso, como simple coordinador de este número de Documentación Administrativa, no me corresponde ir más allá de donde he llegado. Evidentemente, las aportaciones son las que hacen los autores que han participado en su elaboración y a los que desde aquí reitero de nuevo mi agradecimiento.

Simplificando al máximo puede decirse que este número se divide en tres partes bien diferenciadas. La primera se ocupa del planteamiento general del tema: desde la Constitución, desde la realidad económica, desde la teoría de la organización, se analiza la laboralización de la función pública. La segunda analiza perspectivas sectoriales. La tercera se ocupa del Derecho comparado (Italia, Alemania, función pública comunitaria). Además, se incluye un anexo bibliográfico de gran interés.

Ramón PARADA considera que el actual modelo de función pública es uun modelo claramente degenerado». Hoy, afirma, «sólo es posible un régimen de función pública que recupere las exigencias originales de devoción por el servicio y de claro predominio de los intereses públicos sobre los privados de los funcionarios». Lleva a cabo un meticuloso estudio del corporati-

${ }^{\text {to }}$ En esta línea, la Sala Cuarta (de lo Social) del Tribunal Supremo (Sentencia de 21 de julio de 1992), ha hecho algunas consideraciones en orden a la determinación del ámbito propio del Derecho Administrativo (que, por tratarse de esa Sala, no de la de lo Contencioso, merece la pena transcribir):

«Mientras que en las convocatorias de promoción interna la Administración actúa claramente como empresario en el marco de una relación contractual establecida y aplicando normas de indiscutible carácter laboral respecto a un personal que ya tiene la condición de trabajador, no sucede lo mismo con las convocatorias de nuevo ingreso. Aquí, aunque la Administración convocante es la que luego ba de contratar, su actuación es previa al vinculo laboral y predomina en ella el caracter de poder priblico que está obligado a formular una oferta de empleo público en términos fjjados por la ley (artículo 18 de la Ley 30/1984, de 2 de agosto) y dirigida en principio a todos los ciudadanos de acuerdo con las principios de igualdad, mérito, capacidad y publicidad. A diferencia del régimen laboral en el que el principio es la libertad de contratación del empresario, se está actuando aquí una potestad administrativa en orden a la selección del personal, que se regula también predominantemente por normas administrativas... La regulación por el Derecho Administrativo es prevalente en atención a la cualificada presencia de un interés general al que se conecta el ejercicio de una potestad administrativa.» 
vismo de servicio de la función pública como «institución voraz», concepto que, debido a Lewis COSER, se refiere a las instituciones "que demandan un compromiso total de parte de sus miembros». Afirma que «en la reforma de 1964 hay que situar el origen de la actual división del empleo público en personal funcionario y laborabs - algo que también recuerda S. DEL SAZ- con la Ley de 1964 «quedó definitivamente rota la unidad de régimen jurídico del personal de la Administracións; el iniciado proceso de laboralización de la Administración «ya no tendría marcha atrás»; posteriormente "las reformas socialistas de 1984 convirtieron el régimen laboral en una alternativa ordinaria al régimen funcionarial común, asimismo muy laboralizado». Critica la «penetración de un régimen de Derecho laboral (que) ha surgido por imposiciones políticas externas, caso de Alemania, o ha sido fruto de una demagogia obrerista en España, o producto de un diseño de laboratotio como en Italia». Francia, por su parte, «se ha salvadoir. La de PARADA es, en suma, una defensa radical de la función pública basada en el corporativismo de servicio, lejos, pues, de cualquier tentación laboralizadora.

Luciano PAREjo entra en el importantísimo tema de la conexión entre modelo de organización y empleo público. Considera que la desaparición de la singularidad del estatuto de los funcionarios públicos por la vía de su laboralización es un planteamiento erróneo, pues «es claro que la naturaleza de poder público de la Administración y la exorbitancia del régimen jurídico de su organización y actividad reclaman la especificidad del estatuto cuando menos de aquellos empleados públicos que, por razón de sus tareas, participan del ejercicio de aquel poden. Incluso llega a calificar el de la laboralización como uproceso de desnaturalización de la relación jurídica funcionarial» y afirma: «es preciso recuperar con todo énfasis la necesidad y actualidad de un verdadero estatuto de la función pública».

GONZÁlEZ QUINZÁ, tras un detenido repaso de las posiciones doctrinales más significativas, considera que no son posibles posiciones extremas, ni "pro-laboralizantes» ni «profuncionarizantes», por lo que se han de abrir paso posiciones eclécticas. En cualquier caso, considera que el artículo 103.3 de la Constitución «protegió la opción pro-funcionarial con la reserva de ley, pero quedó lejos de imponer un determinado tipo de estatuto».

Señala Catalá Polo, tras analizar con detalle la aproximación de los regímenes, modelos e instituciones entre funcionarios y laborales en las Administraciones Públicas: «La utilización por la Administración de los instrumentos de gestión propios del Derecho privado no implica, tal como se le ha 
denominado, ninguna huida del Derecho Administrativo sino que, por el contrario, se sitúan las relaciones laborales en un entorno coherente con los contenidos de la prestación de servicios que se realizan... (La gestión de acuerdo a técnicas propias del Derecho privado), más que una huida de nada ni de nadie, significa una firme apuesta por un sector público eficaz y legitimado ante la sociedad para la prestación de los servicios que le han sido encomendados».

Silvia DEL SAZ denuncia que «lo más grave de la aplicación del Derecho laboral a la Administración pública (tras la Ley 30/1984) es que se ha hecho sin ningún tipo de límites». Al someterse al régimen laboral algunas de las entidades del 6.5 de la LGP incluso desempeñando funciones públicas, «se ha roto el tradicional monopolio de los funcionarios para ejercer funciones administrativas y hoy el personal laboral de estos organismos, que no tienen otro, puede dictar actos administrativos impugnables ante la Jurisdicción contencioso-administrativay. Plantea asimismo, tras un completo análisis, serias dudas acerca de la legalidad e incluso constitucionalidad de los «blindajes» de los contratos de alta dirección.

Cualquier planteamiento general requiere, sin embargo, ser contrastado con la realidad de la función pública autonómica y local, por una parte, y del empleo público en ámbitos sectoriales de extraordinaria importancia.

En relación con el primer tema, Iñaki LASAGABASTER recuerda que la Ley $30 / 1984$ es la primera norma que «realiza una distribución de competencias» en materia de función pública, si bien el artículo $15.1^{\circ}$, donde se establece la diferencia función pública-contratación laboral no se considera básico. Por otra parte, considera que la STC 99/1987 no puede interpretare en el sentido de que el TC se defina en favor de un modelo funcionarial de empleo público; asimismo, la Constitución uno está pensando (en contra de lo que ocurre con el art. $33.5 .^{\circ}$ de la Constitución alemana) en un modelo concreto de función pública, sino que más bien ha establecido unas exigencias vinculadas al principio de igualdad, que son igualmente aplicables a toda clase de empleos públicos». De modo que la Ley 30/1984 no impone (pues en este punto no es básica: art. 15) la diferenciación restrictiva entre funcionarios y laborales. Las Comunidades Autónomas podrían haber optado por un modelo diferente. Pero ha sido la «afirmación accidental» del TC en la STC 99/1987 la que ha hecho que éstas hayan «optado por una solución continuista, lejos de todo afán experimentadon». Tan sólo en el ámbito de los puestos de dirección se aprecia un mayor recurso 
a la contratación laboral. En cuanto a la función pública local, LASAGABASTER considera que en orden a proceder a una «reforma necesaria» del empleo público local, debería eliminarse «la diferenciación funcionario-contratado laborabs: a modo de tertium genus, entre lo que hoy se considera función pública y la contratación laboral, debería llegarse a «una regulación única del empleo público locals. Ahora bien, respetando siempre la transparencia máxima en la provisión de puestos y garantizando los principios de mérito y capacidad.

$\mathrm{El}$ intento de conseguir una respuesta uniforme para el modelo de empleo público choca sin embargo con la realidad de las regulaciones sectoriales. PALOMAR OLMEDA, que se apoya en datos numéricos irrefutables y de imprescindible toma en consideración, señala que el estatuto general de la función pública sólo se aplica «a un cuarto del conjunto de empleados públicos». Y se plantea esta duda: el mayor uniformismo en la regulación implica menor capacidad de adaptar a la realidad el marco de gestión de recursos humanos, mientras que la mayor flexibilidad supone mayor dispersión normativa y mayor dificultad para encontrar elementos comunes de una política global de empleo público. Ante la heterogeneidad del sistema resalta la necesidad de buscar una disciplina de alcance global y no parcial, que, sin duda, es presupuestaria, pero que también debe referirse a la oferta de empleo, el montante global del gasto en retribuciones, o la conexión entre empleo estable y protección social.

Se analizan a continuación tres modelos comparados: el italiano, el alemán y el comunitario. No otros, que podrían ofrecer también interés: por ejemplo, el francés o el estadounidense. El primero por ser, creo, mejor conocido y optar claramente por el régimen funcionarial. El segundo, por no adaptarse a nuestra realidad.

El Profesor Alfredo CorPaCi analiza el que es sin duda el ejemplo más claro y ambicioso de laboralización del empleo con las Administraciones Públicas: el modelo italiano. Tras un completo estudio histórico, señala que «la especialidad del empleo público entendida como necesaria sumisión... a un régimen de Derecho público, no encuentra en la Constitución un explícito e inequívoco fundamentor. Para determinar los principios constitucionales del empleo público no sólo hay que tomar en consideración los preceptos referidos a la organización administrativa y la función pública, sino también los relativos al trabajo (arts. 35-40), y puede mantenerse que en el texto constitucional se da una "prevalencia de los valores laborales». No obstante, la 
Ley Marco de 1983, pese a reconocer relieve al aspecto laboral (negociación colectiva) «no pone en discusión la naturaleza pública de la relación de empleon, que se somete al Derecho Administrativo y a la competencia del juez administrativo. Sin embargo, la reforma de 1992-1993 es, ésta sí, radical: lleva a cabo una verdadera laboralización del empleo público (la relación de trabajo cambia de naturaleza jurídica: se sustrae al régimen público), que se somete a negociación colectiva; negociación que se traduce en verdaderos convenios, no en actos unilaterales de la Administración. La representación negocial viene atribuida a una Agencia (Agenzia per la rappresentanza Negoziale) y el conocimiento de los asuntos (salvo las materias excluidas de la negociación) se atribuye (se "devuelve») al juez ordinario del trabajo. De modo que, pese a las críticas que desde luego merece en ciertos puntos, la reforma de $1992-93$ es constitucionalmente válida.

Mariano BACIGALupo se ocupa, en un estudio elaborado a partir de las fuentes directas, del modelo alemán. Modelo «dual» en el que conviven dos tipos de personal, el funcionarial y el laboral, en un sistema denominado significativamente "de doble carril» que tiene además anclaje constitucional en la Ley Fundamental de Bonn, artículo 33.4, en la medida en que en éste se reserva a los funcionarios el desempeño de funciones públicas que entrañen ejercicio de potestades. La Ley Federal Marco de los Funcionarios Públicos de 1957 mantiene esta dualidad, pero convierte en reserva de máximos la que en la LFB es reserva de mínimos, por lo que desde entonces es más numeroso el personal laboral que el funcionario. En cualquier caso, la Ley Fundamental de Bonn contiene una garantía institucional del régimen estatutario de la función pública que se reconduce hacia la noción de «ejercicio de potestades o prerrogativas de poder público» que es hasta donde alcanza la reserva constitucional funcionarial. Esta situación, sin embargo, se ha visto alterada con las reformas constitucionales de 1992, 1993 y 1994 que hacen posible la privatización del control aéreo, los ferrocarriles, el correo y las telecomunicaciones, lo cual ha incidido muy decisivamente en el "trasvase o laboralización» del personal funcionario que venía prestando sus servicios en tales ámbitos.

El tercer modelo comparado, muy diferente a los dos anteriores, es el que ofrece la función pública comunitaria. FUENTETAJA PASTOR se ocupa de este modelo de función pública, modelo cerrado y basado en estos elementos esenciales: el régimen estatutario, la estabilidad en el empleo y la carrera. Modelo, pues, fuertemente funcionarizado, en el que sólo desde 1972 se admite 
la sindicación y que no conoce la negociación colectiva, sino un régimen de "concertación", pero admitiendo que las condiciones de empleo son fijadas unilateralmente por el legislador comunitario. Este sistema ha soportado, incluso, la creación de entidades instrumentales descentralizadas ("Agencias»), cuyo personal se encuentra sometido a las mismas reglas que el resto de los funcionarios comunitarios, al objeto de "garantizar la máxima coherencia posible a escala comunitaria en materia de gestión de personaly, como ha señalado en alguna ocasión concreta la propia Comisión. La función pública comunitaria presenta, pues, un ejemplo claro de mantenimiento del régimen estatutario que apenas se pone en cuestión (aunque seguramente algo tendrá que ver el hecho de que los funcionarios comunitarios gozan de una situación que puede muy bien calificarse de privilegiada desde muchos puntos de vista).

Por último, Josefa CANTERO ofrece una relación bibliográfica seleccionada sobre empleo público en España, Francia e Italia. Relación que, por supuesto, no puede ni pretende ser completa aunque sí, por seleccionada, significativa.

Creo que la visión que se da del estado de la cuestión de la laboralización del empleo con las Administraciones Públicas es suficientemente indicativa. Creo asimismo que se deja claro lo que apuntaba al principio: el modelo de empleo público es complejo, abierto y en elaboración. Intentar mantener dogmas o criterios exclusivamente jurídicos no es fácil. El sentido del servicio público y de la dedicación al interés general siguen siendo elementos esenciales en la determinación del régimen aplicable a los empleados de las Administraciones Públicas. El paradigma de la laboralización no se sustenta con tanta base como en alguna ocasión se ha pretendido. Sin olvidar que, como intentaba demostrar páginas atrás (y sale a relucir en más de uno de los trabajos que se incorporan a esta Revista), el Derecho Administrativo debe aplicarse cuando estemos ante el ejercicio de potestades o prerrogativas, lo que condiciona cualquier intento (legítimo, por lo demás) de privatización de la función pública. En cualquier caso, lejos de existir una solución más o menos homogénea para hacer frente a la constante redefinición del sistema de empleo público, encontramos múltiples intentos, a veces contradictorios y muy poco dogmáticos, de dar respuesta a las demandas que se plantea la Administración y que los ciudadanos requieren. Desde el modelo más funcionarializado al 
más laboralizado todos tienen cabida en el ámbito de regímenes jurídicos semejantes. Sin olvidar que, pese a lo que en principio pudiera pensarse, un modelo general para las Administraciones Públicas españolas no existe, pues son tantas las excepciones de régimen, que al final lo general termina casi por ser excepcional. 
DA-1995, núm. 243. JOSÉ LUIS PIÑAR MAÑAS. El modelo de función pública como sistema comple...

Estudios

DA-1995, núm. 243. JOSÉ LUIS PIÑAR MAÑAS. ẸI modelo de función pública como sistema comple... 
DA-1995, núm. 243. JOSÉ LUIS PIÑAR MAÑAS. El modelo de función pública como sistema comple...

DA-1995, núm. 243. JOSÉ LUIS PIÑAR MAÑAS. El modelo de función pública como sistema comple... 